\title{
PREDICTION OF CHANGE IN HYDROLOGIC CYCLE COMPONENTS IN NORTH KOREA RIVER BASINS: THE RCP8.5 CLIMATE CHANGE SCENARIO
}

\author{
SE JIN JEUNG, BO RA KWON \& BYUNG SIK KIM \\ Department of Urban and Environmental Disaster Prevention Engineering, Kangwon National University, \\ Republic of Korea
}

\begin{abstract}
North Korea is particularly vulnerable to natural disasters related to climate change, such as flooding and drought, as its forest ecosystem has been damaged as a result of excess development due to food and energy shortage. To prepare for potential natural disasters and to come up with effective countermeasures against climate change, it is crucial to make use of systematic and scientific weather and climate forecasting information in the best possible way. However, it is difficult to find hydrologic data for North Korea, and direct observations of the nation's hydrology are practically impossible to make. Therefore, because of the difficulties in collecting hydrological data, studies on climate change and hydrology in North Korea are rarely conducted. This study collected precipitation and temperature data from 27 weather stations located in North Korea (provided by the World Meteorological Organization), and used the RCP8.5 climate change scenario of the Korean Meteorological Administration to calculate potential future evapotranspiration for each station. The study applied a lumped conceptual model (Water And Snow Balance MODeling system (WASMOD)) to North Korea's representative river basins (Daedong River, Aprok River) to obtain a supplementary hydrologic data time series through doing calculations based on the calculated time series data of the future hydrologic cycle components of North Korea. The study analyzed the impact of climate change on the hydrologic cycle process of North Korea using the RCP8.5 climate change scenario, and predicted its influence on water resources at a river basin scale.
\end{abstract}

Keywords: RCP8.5 climate change scenario, North Korea, hydrological cycle components, time series analysis.

\section{INTRODUCTION}

Climate change is occurring faster than the global average in the Korean peninsula. For example, typhoons, extreme rainfall, heavy snow, cold waves, and global warming are becoming more and more frequent. In particular, forested areas in North Korea have been damaged due to food and energy shortages. They are vulnerable to climate-change-related natural disasters such as floods and droughts. To prepare for the expected large-scale natural disasters and to efficiently cope with climate change, it is very important to utilize systematic and scientific weather and climate forecasting data.

Although plenty of studies on climate change are conducted worldwide, research on changes to North Korea's hydrological cycle due to climate change are scarce. There are such difficulties in direct collection and measurement of North Korea's hydrological data due to the political, social, and cultural issues surrounding the nation. Accordingly, in this paper, we collected the precipitation and temperature data from 27 North Korean sites provided by the World Meteorological Organization (WMO), to analyze the historical climate characteristics of the Daedong River Basin and the Amnok River Basin in North Korea. In addition, using the RCP 8.5 climate change scenario provided by the Korea Meteorological Administration (KMA), we predicted the future climate characteristics of North Korea. Under the RCP 8.5 climate change scenario, we also analyzed the impact of climate change on the hydrological cycle in North Korea and predicted the effects of climate change on 


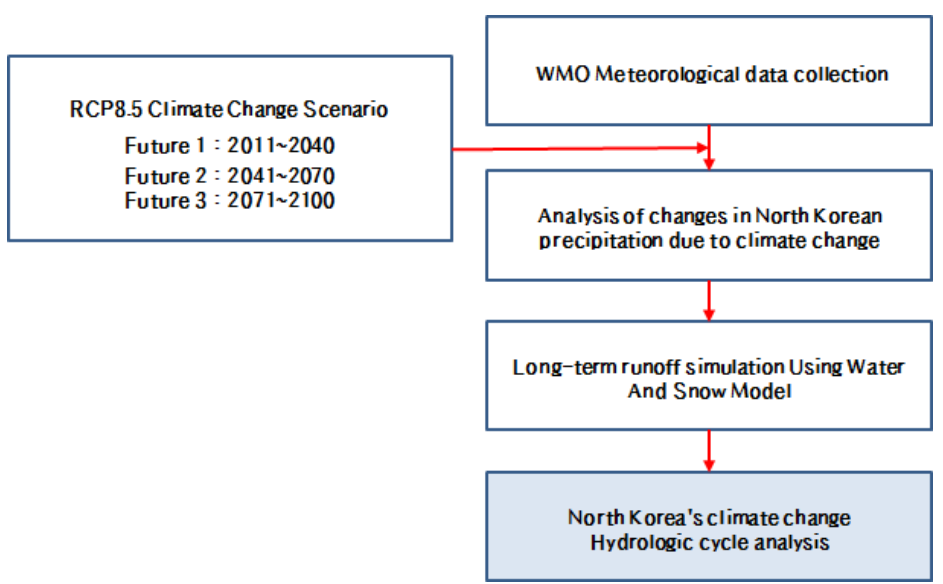

Figure 1: Research flowchart.

watershed-scale water resources by applying the scenario to the lumped conceptual model "WASMOD."

\section{THEORETICAL BACKGROUND}

\subsection{RCP climate change scenario}

There are four types of RCP scenarios: RCP 8.5, where the current anthropogenic GHGs emission trends continue (BAU); RCP 2.6, with the maximum limit for the earth to maintain resilience; and RCP 4.5/6.0, where the GHGs mitigation policies are somewhat realized (IPCC [1]). The prefix numbers indicate the amount of radiative forcing and the unit is Wm2. The radiative forcing of RCP 8.5, 6.0, 4.5, and 2.6 corresponds to about $3.6 \%, 2.5 \%, 1.9 \%$, and $1.1 \%$ of the incident solar radiation as the solar radiation reaching the ground is about $238 \mathrm{Wm}-2$.

The East Asian region, where Korea is located, shows large-scale climate variability due to its complex geographical characteristics. The frequency and intensity of the extreme climate tends to increase with climate change. To deal with the changing climate, studies on climate change impact assessment, adaptation, and vulnerability are carried out regularly in various fields such as hydrology, agriculture, construction, and environment in Korea. At this point, detailed and reliable regional climate change information for the present and future is most important. Accordingly, the National Institute of Meteorological Research has developed a high-resolution regional climate scenario for the Korean region in response to climate change on a national level.

The process of high-resolution regional climate change scenario calculations passes through two stages. First, HadGEM2-AO, a global atmospheric-ocean coupled model, produces a global climate change scenario with an approximate resolution of $135 \mathrm{~km}$, based on the RCP scenario, which is a new GHG emission scenario. Then, regional climate model HadGEM3-RA yields two scenarios, based on the global climate change scenario data: the regional climate change scenario with a $50-\mathrm{km}$ resolution for East Asia; and the regional climate change scenario with a $12.5-\mathrm{km}$ resolution for the Korean region. In this study, we predicted the future hydrological cycle variability of North Korea, using the RCP8.5 climate change scenario of the regional climate model "HadGEM3-RA." 


\subsection{WASMOD model}

The four major processes in the water cycle are precipitation, evapotranspiration and infiltration, surface runoff, and groundwater runoff. The water cycle process does not mean that water continuously moves between constituent processes in sequence. It is common for the water cycle process to be temporally and spatially variable. The runoff caused by precipitation is a complicated hydrological phenomenon, taking into consideration the spatial and temporal change in precipitation, ununiformed land conditions, and various hydrological characteristics, depending on soil characteristics. As it is impossible to accurately express all of these natural phenomena using a mathematical formula, we conceptually simplify the runoff phenomenon in the WASMOD model, as in most other water models.

The WASMOD model uses the "temperature index function" proposed and introduced by Vandewiele et al. [2] to classify precipitation into rainfall and snowfall. The snow storage of the previous month is combined with the snowfall. Some of the combined snow (storage retention) will melt as the temperature slowly rises, thus contributing to soil moisture retention. In addition, some of the rainfall is lost through evapotranspiration, and the remaining amount is defined as actual rainfall. Such actual rainfall contributes to the soil moisture retention $(\mathrm{Xu}[3])$.

\section{APPLICATION RESULT}

\subsection{Analysis of watershed status}

The Daedong River, the study area, is the fifth longest river in the Korean Peninsula. As an asymmetric watershed with many tributaries on the left bank, the river has a total of 443 tributaries, among which 26 tributaries are over $15 \mathrm{~km}$ long. The watershed length is $438 \mathrm{~km}$, and the area is about $19,377 \mathrm{~km}^{2}$ (Fig. 2(a)). The Amnok River is an international river that originates from Mt. Baekdu and forms the border between the Korean Peninsula and the northeast part of China. A number of rivers and tributaries form over $100 \mathrm{~km}$ of the Amnok River, among them Hecheon River, Jangjin River, Bujeon River, Jaseong River, Dogro River, Chungman River, and Samgyocheon Stream. It flows into the Yellow Sea from the lower part of Yongampo after passing through Hyesan, Junggangjin, Manpo, Sinuiju, and so on. The length of the watershed is $803.3 \mathrm{~km}$, and the watershed area (including the part in China) is about $64,841 \mathrm{~km}^{2}$ (Fig. 2(b)). Table 1 shows the status of the weather stations in the Daedong River Basin and the Amnok River Basin.

\subsection{Analysis of change in climate characteristics of North Korea based on RCP8.5 climate change scenarios}

The study analyzed the future climate variability in the North Korean watershed (Daedong River and Amnok River) using the RCP 8.5 climate change scenario. First, data on precipitation and temperature for the past (1981-2014) and for the future (2011-2100) that were collected by WMO were divided into three periods: Future 1 from 2011 to 2040; Future 2 from 2041 to 2070; and Future 3 from 2071 to 2100. Then, the study identified future climate variability compared this to the current level.

According to the result of the analysis, the average annual rainfall of the Daedong River Basin is projected to be about $920.6 \mathrm{~mm}$ (4.3\% decrease from the current level) in Future 1, while it is about $1016.7 \mathrm{~mm}(5.7 \%$ increase from the current level) in Future 2, and about $1081.2 \mathrm{~mm}$ (12.4\% increase) in Future 3. The temperature was projected to increase by approximately $50 \%$ compared to the current level (Table 2, Fig. 3.) The average annual 
rainfall in the Amnok River Basin is projected to be about $1235.9 \mathrm{~mm}$ (45.5\% increase from the current level) in Future 1, while it is about 1,334.8 $\mathrm{mm}(55 \%$ increase from the current level) in Future 2, and about $1460.1 \mathrm{~mm}(69.5 \%$ increase from the current level) in Future 3. The temperature was projected to increase by approximately up to $74.2 \%$ compared to the current level (Table 3, Fig. 4).

3.3 Prospects for future change of hydrological circulation in North Korea using RCP 8.5 climate change scenario

In this chapter, the RCP 8.5 climate change scenario will be applied to predict the impact of climate change on the hydrological cycle in North Korea (Daedong River and Amnok River). Similar to the previous analysis, the study divided the future period from 2011 to 2100 into three periods: Future 1 from 2011 to 2040; Future 2 from 2041 to 2070; and Future 3 from 2071 to 2100 . Also, the RCP 8.5 climate change scenario was applied to the WASMOD

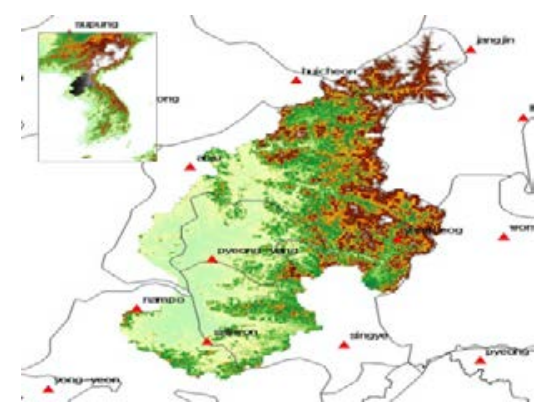

(a) Daedong River

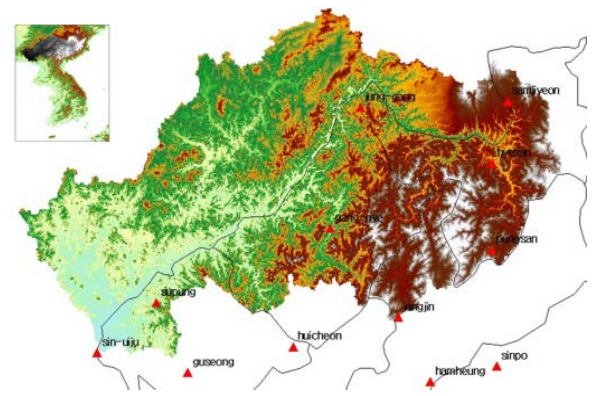

(b) Amnok River

Figure 2: Locations of the weather stations used in this study.

Table 1: Weather stations used in this study.

\begin{tabular}{|l|l|l|l|l|}
\hline Basin & Station & TM_X & TM_Y & Data Period \\
\hline \multirow{4}{*}{ Daedong River } & Nampo & 57709.0 & 580814.7 & $1981-2014$ \\
\cline { 2 - 5 } & Pyongyang & 94414.7 & 615401.8 & $1981-2014$ \\
\cline { 2 - 5 } & Sariwon & 92196.6 & 558068.8 & $1981-2014$ \\
\cline { 2 - 5 } & Yangdeok & 185348.1 & 629508.5 & $1981-2014$ \\
\hline \multirow{5}{*}{ Amnok River } & Sinuiju & -23353.9 & 736399.4 & $1981-2014$ \\
\cline { 2 - 5 } & Supung & 24453.0 & 774026.6 & $1981-2014$ \\
\cline { 2 - 5 } & Kanggye & 166089.7 & 829416.0 & $1981-2014$ \\
\cline { 2 - 5 } & Jangjin & 220985.8 & 762745.9 & $1981-2014$ \\
\cline { 2 - 5 } & Poongsan & 296768.5 & 813315.1 & $1981-2014$ \\
\cline { 2 - 5 } & Hyesan & 297309.3 & 878111.1 & $1981-2014$ \\
\cline { 2 - 5 } & Samjiyeon & 309147.1 & 924564.2 & $1981-2014$ \\
\cline { 2 - 5 } & Junggang & 190062.2 & 920034.8 & $1981-2014$ \\
\hline
\end{tabular}




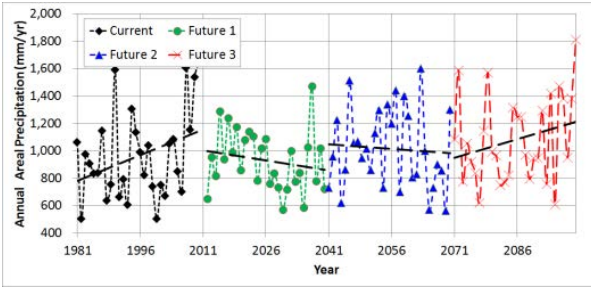

(a) Annual Precipitation

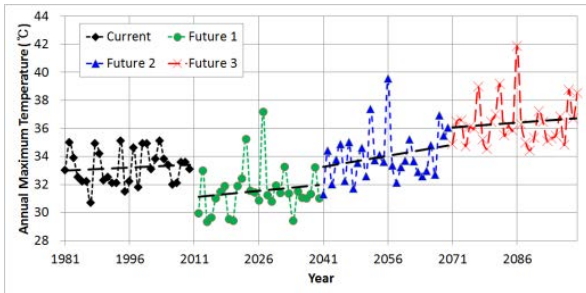

(c) Annual Maximum Temperature

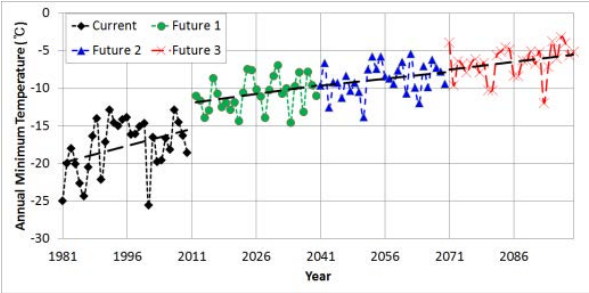

(b) Annual Minimum Temperature

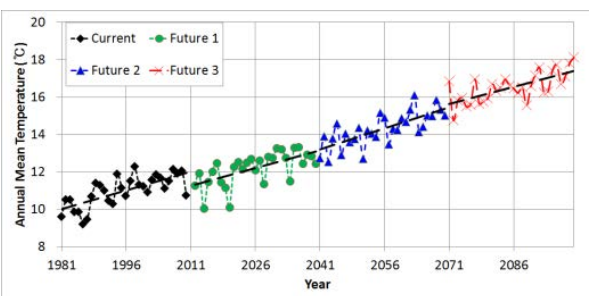

(d) Annual Mean Temperature

Figure 3: Analysis of changes in trends of future precipitation and temperature compared to present (Daedong River).

Table 2: Analysis of changes in future climate characteristics compared to present (Daedong River).

\begin{tabular}{|l|l|l|l|l|l|l|l|l|}
\hline & \multicolumn{3}{l}{ Current } & \multicolumn{3}{l}{ Future 1 } & Future 2 & \multicolumn{2}{l|}{ Future 3 } \\
\cline { 2 - 9 } & Mean & Trend & Mean & Trend & Mean & Trend & Mean & Trend \\
\hline $\begin{array}{l}\text { Annual } \\
\text { precipitation } \\
(\mathrm{mm})\end{array}$ & 961.5 & 12.56 & 920.6 & -6.3 & 1016.7 & -2.22 & 1081.2 & 9.03 \\
\hline $\begin{array}{l}\text { Annual minimum } \\
\text { temp. }\left({ }^{\circ} \mathrm{C}\right)\end{array}$ & -25.6 & 0.15 & -14.5 & 0.07 & -13.83 & 0.06 & -11.97 & 0.07 \\
\hline $\begin{array}{l}\text { Annual } \\
\text { maximum } \\
\text { temp. }\left({ }^{\circ} \mathrm{C}\right)\end{array}$ & 35.1 & 0.01 & 37.1 & 0.05 & 39.5 & 0.05 & 41.89 & 0.02 \\
\hline $\begin{array}{l}\text { Annual } \\
\text { mean } \\
\text { temp. }\left({ }^{\circ} \mathrm{C}\right)\end{array}$ & 10.9 & 0.07 & 12.2 & 0.07 & 14.2 & 0.07 & 16.51 & 0.06 \\
\hline
\end{tabular}




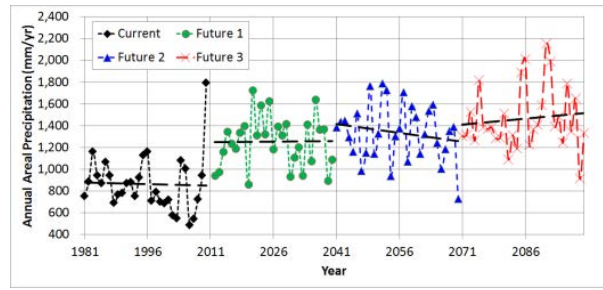

(a) Annual Precipitation

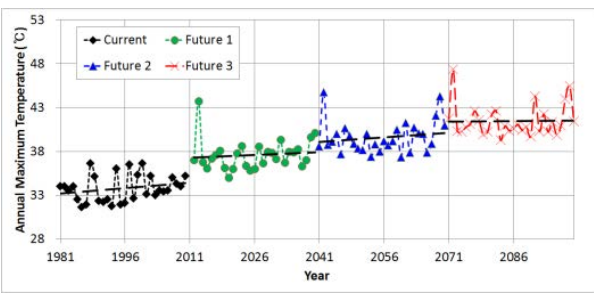

(c) Annual Maximum Temperature

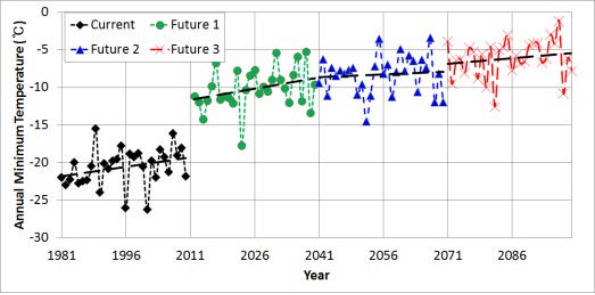

(b) Annual Minimum Temperature

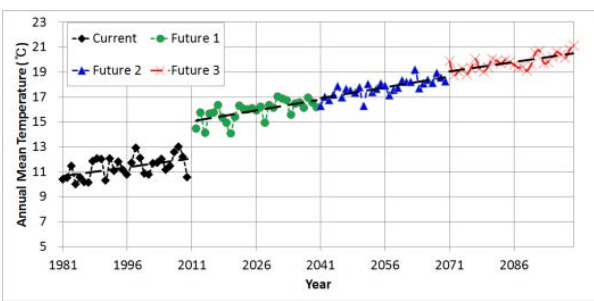

(d) Annual Mean Temperature

Figure 4: Analysis of changes in trends of future precipitation and temperature compared to present (Amnok River).

Table 3: Analysis of changes in future climate characteristics compared to present (Amnok River).

\begin{tabular}{|c|c|c|c|c|c|c|c|c|}
\hline & \multicolumn{2}{|c|}{ Current } & \multicolumn{2}{|c|}{ Future 1} & \multicolumn{2}{|c|}{ Future 2} & \multicolumn{2}{|c|}{ Future 3} \\
\hline & Mean & Trend & Mean & Trend & Mean & Trend & Mean & Trend \\
\hline $\begin{array}{l}\text { Annual } \\
\text { precipitation } \\
(\mathrm{mm})\end{array}$ & 861.4 & -0.89 & 1235.9 & -3.05 & 1334.8 & -5.41 & 1460.1 & 3.59 \\
\hline $\begin{array}{l}\text { Annual } \\
\text { minimum temp } \\
\left({ }^{\circ} \mathrm{C}\right)\end{array}$ & -26.3 & 0.08 & -17.8 & 0.08 & -14.6 & 0.02 & -12.6 & 0.05 \\
\hline $\begin{array}{l}\text { Annual } \\
\text { maximum temp } \\
\left({ }^{\circ} \mathrm{C}\right)\end{array}$ & 36.6 & 0.04 & 43.8 & 0.02 & 44.8 & 0.04 & 47.4 & 0.01 \\
\hline $\begin{array}{l}\text { Annual mean } \\
\text { temp. }\left({ }^{\circ} \mathrm{C}\right)\end{array}$ & 11.4 & 0.05 & 16.0 & 0.06 & 17.7 & 0.06 & 19.8 & 0.05 \\
\hline
\end{tabular}

model to estimate long-term runoff. Based on the analyzed long-term runoff, the study compared the future average monthly precipitation (rainfall, snowfall), and predicted the baseflow, surface runoff characteristics, seasonal runoff, and monthly runoff change.

In the case of the Daedong River, the average annual precipitation decreased by $4.2 \%$ in Future 1, while it increased by $4.8 \%$ in Future 2. In Future 3, it increased by about $10.2 \%$. The annual runoff decreased by $4.3 \%$ in Future 1, while it increased by $4.8 \%$ in Future 2 by $8.9 \%$ in Future 3 (Table 4). Figs 5 and 6 show the monthly rainfall and runoff characteristics of the Daedong River Basin. 
In the case of the Amnok River, the average annual precipitation increased by $29.6 \%$ under Future 1, while it increased by $55.3 \%$ under Future 2 and by $72.1 \%$ under Future 3 . The annual runoff increased by $48.5 \%$ under Future 1, while it increased by $20.1 \%$ under Future 2 and by $26.6 \%$ under Future 3 (Table 5). Figs 7 and 8 show the monthly rainfall and runoff characteristics of the Amnok River basin.

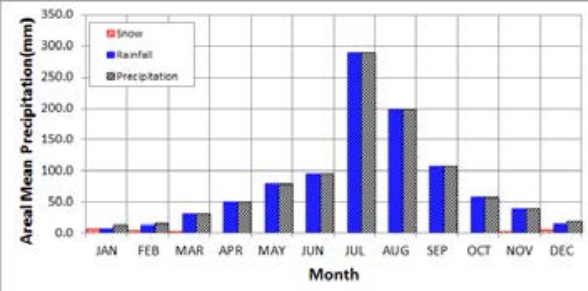

(a) Current

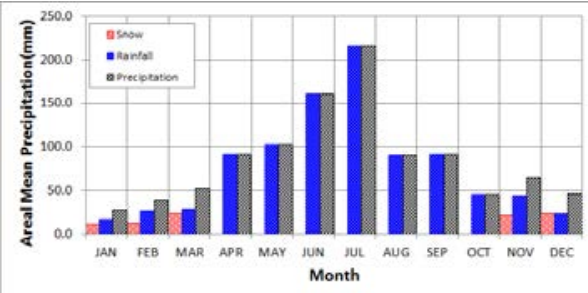

(c) Future 2

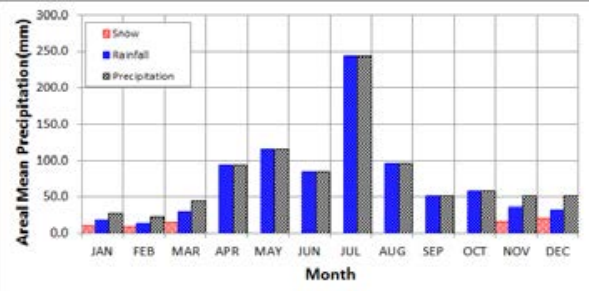

(b) Future 1

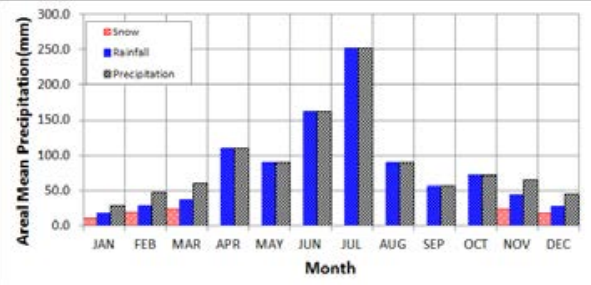

(d) Future 3

Figure 5: Monthly rainfall characteristics (rainfall, snowfall) analysis result (Daedong River).

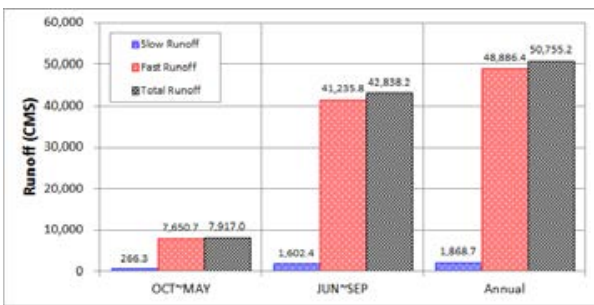

(a) Current

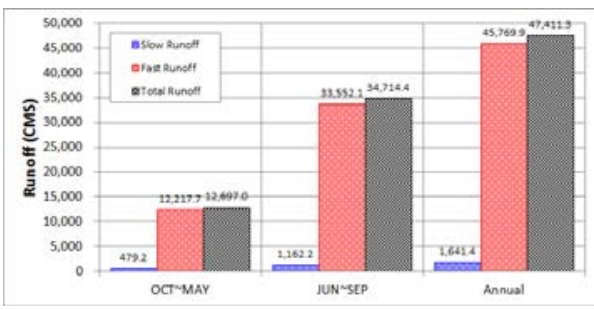

(c) Future 2

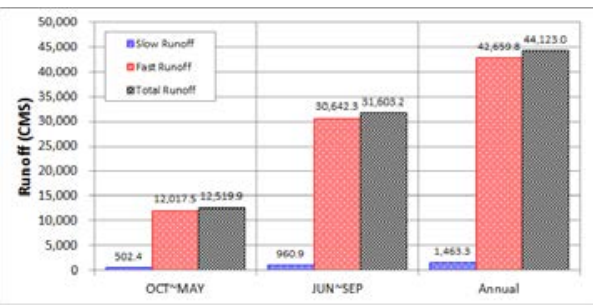

(b) Future 1

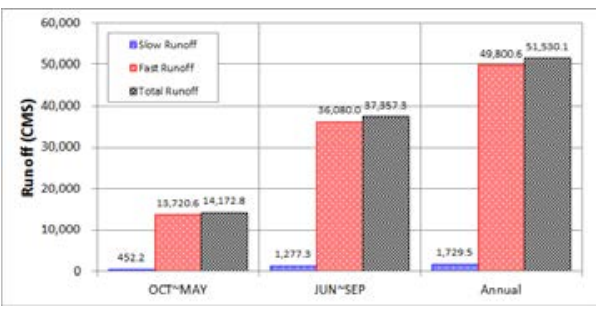

(d) Future 3

Figure 6: Seasonal runoff characteristics (fast flow, slow flow) analysis results (Daedong River). 
Table 4: Runoff simulation results (Daedong River).

\begin{tabular}{|l|l|l|l|l|}
\hline & Current & Future 1 & Future 2 & Future 3 \\
\hline Precipitation (mm) & 974.6 & 933.3 & $1,021.8$ & $1,073.8$ \\
\hline Rainfall(mm) & 961.5 & 866.8 & 931.7 & 981.2 \\
\hline Snowfall(cm) & 1.3 & 66.5 & 90.1 & 92.6 \\
\hline Runoff(CMS) & $215,525.1$ & $206,315.5$ & $225,902.4$ & $238,114.9$ \\
\hline Slow Runoff(CMS) & $7,695.0$ & $7,543.4$ & $8,160.1$ & $8,155.6$ \\
\hline Fast Runoff(CMS) & $207,830.1$ & $198,772.1$ & $217,742.3$ & $229,959.2$ \\
\hline
\end{tabular}

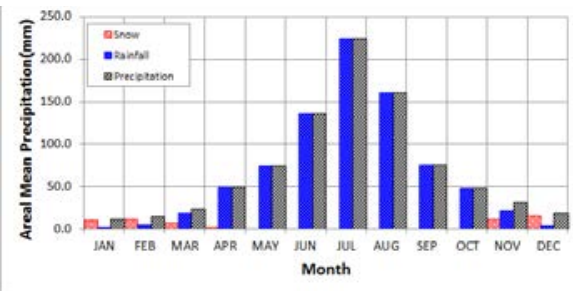

(a) Current

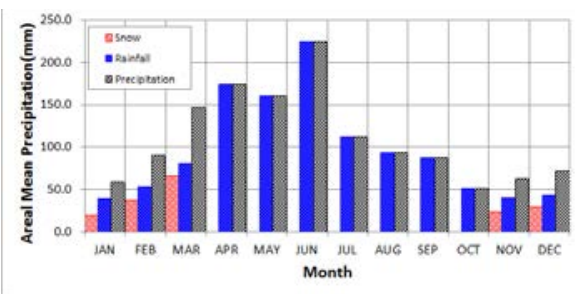

(c) Future 2

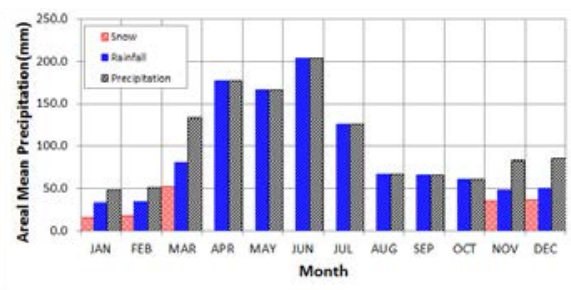

(b) Future 1

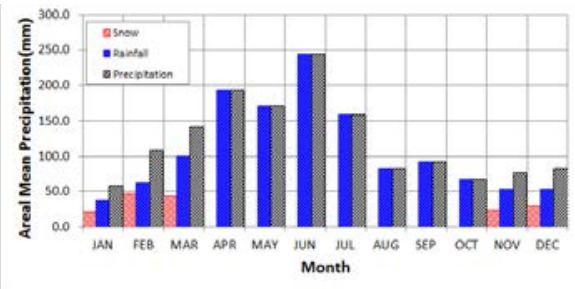

(d) Future 3

Figure 7: Monthly rainfall characteristics (rainfall, snowfall) analysis result (Amnok River).

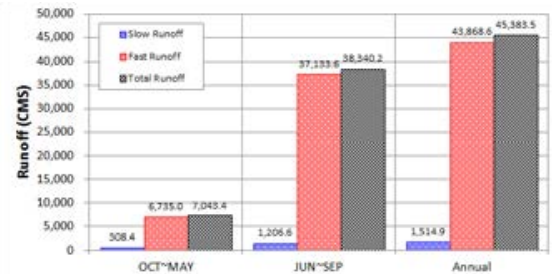

(a) Current

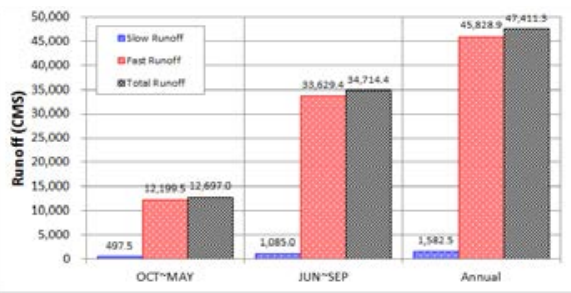

(c) Future 2

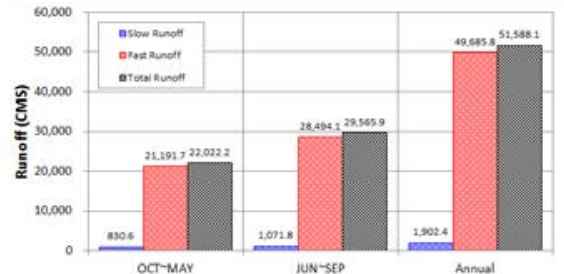

(b) Future 1

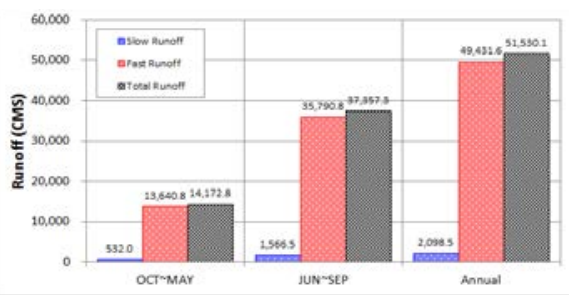

(d) Future 3

Figure 8: Seasonal runoff characteristics (Fast flow, Slow flow) analysis results (Amnok River). 
Table 5: Runoff simulation results (Amnok River).

\begin{tabular}{|l|l|l|l|l|}
\hline & Current & Future 1 & Future 2 & Future 3 \\
\hline Precipitation (mm) & 853.4 & $1,259.3$ & $1,325.1$ & $1,469.0$ \\
\hline Rainfall (mm) & 805.9 & $1,105.6$ & $1,151.8$ & $1,307.7$ \\
\hline Snowfall (cm) & 4.7 & 153.7 & 173.3 & 161.4 \\
\hline Runoff (CMS) & $188,132.1$ & $279,413.4$ & $225,902.4$ & $238,114.9$ \\
\hline Slow Runoff (CMS) & $6,526.6$ & $10,258.8$ & $7,907.9$ & $9,291.2$ \\
\hline Fast Runoff (CMS) & $181,605.5$ & $269,154.5$ & $217,994.5$ & $228,823.7$ \\
\hline
\end{tabular}

\section{CONCLUSION}

The study classified North Korea as an unmeasured area, where direct hydrological measurement is limited due to political and social reasons. In addition, the study tried to analyze future changes in the water cycle elements of the North Korean area. To this end, the study collected the precipitation and temperature data of North Korea provided by WMO and applied the RCP 8.5 climate change scenario provided by KMA. To analyze the changes in the weather characteristics of North Korea, the future period was divided into three: Future 1 from 2011 to 2040; Future 2 from 2041 to 2070; and Future 3 from 2071 to 2100 . The study used the WASMOD model, a conceptual water balance model, to predict future changes in the water cycle elements of North Korea. The results are as below.

First, changes in the rainfall characteristics of the Daedong River Basin and the Amnok River Basin of North Korea were analyzed. The average annual rainfall of the Daedong River Basin is projected to decrease by $4.3 \%$ from the current level in Future 1, while it will increase by $5.7 \%$ in Future 2 and by $12.4 \%$ in Future 3 . The temperature was projected to increase by approximately up to $50 \%$ compared to the current level. The average annual rainfall in the Amnok River Basin is projected to increase by $45.5 \%$ from the current level in Future 1, while it will increase by 55\% in Future 2 and by $69.5 \%$ in Future 3 . The temperature was projected to increase by approximately up to $74.2 \%$ compared to the current level.

The study applied the RCP8.5 climate change scenario to the WASMOD model. The result showed that the annual runoff of Daedong River decreased by $4.3 \%$ in Future 1, while it increased by $4.8 \%$ in Future 2 and by $8.9 \%$ in Future 3. The annual runoff of Amnok River increased by $48.5 \%$ in Future 1, while it increased by $20.1 \%$ in Future 2. In Future 3, it was found to have significantly increased - by $26.6 \%$. As a result of analyzing the characteristics of the monthly rainfall in North Korea, it was predicted that the possibility of snowfall would increase in the future. As a result of analyzing the seasonal runoff characteristics, it is expected that in the future, summer rainfall will decrease compared to the current level, thus bringing a high possibility of drought.

The purpose of this study is to produce basic data for analyzing the water resources of North Korea and to identify its hydrological cycle variability in preparation for future unification. Based on the results of the analysis, the study found that the characteristics of the hydrological cycle elements in North Korea are significantly changed with the changing climate as in South Korea. As a result, North Korea is also expected to be in need of 
systematic and scientific adaptation in response to climate change. By supplementing the insufficient hydrological time series data, other studies can make use of this data in the future for analyses of water resources and impact assessments in North Korea.

\section{ACKNOWLEDGEMENT}

This research was supported by a grant(14AWMP-B082564-01) from Advanced Water Management Research Program funded by Ministry of Land, Infrastructure and Transport of Korean government.

\section{REFERENCES}

[1] IPCC, Climate Change 2007: The Physical Science Basis. Contribution of Working Group I to the Fourth Assessment Report of the Intergovern mental Panel on Climate Change, S. Solomon et al. (eds)., Cambridge University Press, Cambridge, United Kingdom and New York, NY, USA, 2007.

[2] Vandewiele, G.L. \& Ni-Lar-Win, Methodology and comparative study of monthly water balance models in Belgium, China, Burma. Journal of Hydrology, 134, pp. 315347, 1993.

[3] $\mathrm{Xu}, \mathrm{C} . Y .$, Application of water balance models to different climate regions in china for water resources assessment. Water Resources Management, 11, pp. 51-67, 1996. 